\title{
Efeitos do plasma sanguíneo sobre o crescimento, desenvolvimento bacteriano e estrutura intestinais de leitões desmamados aos 28 dias de idade ${ }^{1}$
}

\author{
Effects of spray dried plasma on wall structure and microbiological development in the \\ gut of piglets weaned at 28 days of age
}
BARBOSA, Fellipe Freitas ${ }^{2}$; FERREIRA, Aloízio Soares ${ }^{3}$; SILVA, Francisco Carlos de Oliveira $^{4}$; CAMPOS, Priscila Furtado ${ }^{2}$; RODRIGUES, Valéria Vânia ${ }^{2}$; OLIVEIRA JÚNIOR, Gregório Murilo de ${ }^{2}$; SCOTTÁ, Bruno Andreatta ${ }^{2}$

\footnotetext{
${ }^{1}$ Parte da tese de doutorado do primeiro autor, apoiado pela Fapemig.

${ }^{2}$ Universidade federal de Viçosa, Programa de Pós-Graduação em Zootecnia, Viçosa, Minas Gerais, Brasil.

${ }^{3}$ Universidade federal de Viçosa, Departamento de Zootecnia, Viçosa, Minas Gerais, Brasil.

${ }^{4}$ Empresa de Pesquisa Agropecuária de Minas Gerais, Viçosa, Minas Gerais, Brasil.

*Endereço para correspondência: fcosilva@epamig.br
}

\section{RESUMO}

Visando-se determinar se o plasma sangüíneo tem efeitos sobre o crescimento, o desenvolvimento bacteriano e a estrutura intestinal de leitões desmamados aos 28 dias de idade consumindo quantidades iguais de dietas, 24 leitões desmamados aos 28 dias de idade foram utilizados em um experimento com delineamento em blocos ao acaso com quatro tratamentos (dietas com 0,$0 ; 2,5 ; 5,0$ e $7,5 \%$ de plasma sangüíneo), seis repetições e um animal por unidade experimental. Foram constatadas diferenças significativas entre os tratamentos em relação aos ganhos de peso, às conversões alimentares e às quantidades de colônias de $E$. coli. Os animais que consumiram as dietas com plasma sangüíneo apresentaram maiores ganhos de peso, melhores conversões alimentares e menores quantidades de $E$. coli no intestino delgado do que os animais que receberam dietas sem plasma. Não se observou efeitos significativos das quantidades de plasma sangüíneo consumido sobre a estrutura intestinal dos leitões doze dias após o desmame. Concluiu-se que a inclusão de plasma sangüíneo na proporção mínima de 2,5\% aumenta ganho de peso, melhora conversão alimentar e reduz a incidência de colônias de $E$. coli no intestino de leitões desmamados aos 28 dias de idade criados em condições de desafio, mas não afeta a estrutura intestinal.

Palavras-chaves: desmame precoce, diarréias, Escherichia coli, idade ao desmame, enriquecimento nutricional

\section{SUMMARY}

In order to evaluate the effects of spray-dried plasma on performance (weight gain, feed intake, and feed conversion), growth, intestinal health (microflora colonization and intestinal wall morphology) of piglets fed equal amounts per day of feed, 24 piglets weaned at 28 days old were used in an experiment performed as a randomised block design with four treatments (diets with $0.0,2.5,5.0$ and $7.5 \%$ inclusion of spray-dried plasma), six replicates and one animal per experimental unit. Significant differences were observed among treatments weight gain, feed conversion and numbers of $\mathrm{E}$. coli colony forming-units (CFU). Pigletsfed diets with different levels of spray-dried plasma had higher weight gain, better feed conversion and lower amounts of E. coli CFU in the small intestine than animals fed diets without spraydried plasma in the diets. No significant effect of the treatments on the intestinal wall morphology at day twelve after weaning was observed. In conclusion, the inclusion of $2.5 \%$ spray-dried plasma in the diets in creases weight gain, improves feed conversion and reduces the incidence of $\mathrm{E}$. coli $\mathrm{CFU}$ in the small intestine of piglets weaned at 28 days of age reared under challenging conditions, however, no beneficial effect on the intestinal wall morphology was observed with the inclusion of spray dried plasma in the diets.

Keywords: diarrhea, early weaning, Escherichia coli, nutritional enrichment, weaning age 


\section{INTRODUÇÃO}

Tem-se atribuído ao plasma sangüíneo, efeito estimulante na ingestão de dietas pós desmame quando estes são desmamados com 21 dias de idade (GATTAS et al., 2008), mas a ingestão de alimento por si só pode não assegurar o desenvolvimento necessário e adequado para o leitão após o desmame. Por isso, aspectos relacionados com a saúde do leitão no momento do desmame em qualquer idade devem ser considerados.

Os leitões não são capazes de produzir sua própria atividade imunológica de forma eficiente antes dos 42 dias de idade. Portanto, qualquer estresse, problema digestivo, de manejo ou esses fatores combinados, podem fazer com que o sistema de defesa do animal seja ativado para neutralizá-los antes que estes possam colocar em perigo a vida dos leitões. A ativação do sistema imune pode afetar os processos metabólicos e o crescimento, pela interação com o sistema nervoso central, com o sistema endócrino mediante a liberação de corticosteróides e tiroxina e com o sistema endócrino mediante liberação de citocinas (peptídeos imunoreguladores) pelos leucócitos (KLASING et al., 1991).

Ao plasma sanguíneo adicionado às dietas pós-desmame tem-se atribuído a menor capacidade de estimular a resposta imune em leitões nas duas primeiras semanas após o desmame aos 21 dias de idade (COFFEY \& CROMWELL, 2001; BARBOSA et al., 2007). As respostas positivas atribuídas ao plasma sangüíneo podem estar relacionadas à presença de imunoglobulinas específicas (CAMPBELL et al., 2010) que podem diminuir os efeitos adversos da proliferação bacteriana, como a ocorrência de diarréias e alterações na ultra-estrutura de vilosidades no intestino dos animais. Entretanto, são poucos os estudos com leitões desmamados aos 28 dias ou mais, sendo que os efeitos do plasma sangüíneo sobre a estrutura intestinal e sobre a ocorrência de diarréias foram contraditórios, com efeitos significativos apenas sobre $\mathrm{o}$ desempenho dos animais. Uma vez que a eficiência de ganho de peso dos leitões está positivamente associada ao comprimento do intestino (ROPPA, 1998), quanto mais comprido maior será sua área para absorção, fatores que afetam adversamente o desenvolvimento morfológico do tecido intestinal podem prejudicar $\mathrm{o}$ desempenho dos leitões (CERA et al., 2010).

Assim, verificaram-se os efeitos do plasma sobre o desenvolvimento, a ultra-estrutura intestinal e sobre o número de unidades formadoras de colônias de $E$. coli em leitões desmamados aos 28 dias de idade, independentemente do consumo voluntário de ração.

\section{MATERIAL E MÉTODOS}

O experimento foi conduzido no Setor de Suinocultura do Departamento de Zootecnia do Centro de Ciências Agrárias da Universidade Federal de Viçosa, em Viçosa, Minas Gerais, no período de julho a outubro de 2007.

Foram utilizados 24 leitões desmamados aos 28 dias de idade distribuídos em delineamento em blocos ao acaso com quatro tratamentos, seis repetições e um animal por unidade experimental. O critério para formação dos blocos foi o peso do animal ao desmame. Os tratamentos usados foram 
rações com 0,$0 ; 2,5 ; 5,0$ e 7,5\% de inclusão de plasma sangüíneo.

Os valores de composição de alimentos, as relações entre os aminoácidos metionina, treonina e triptofano digestíveis com lisina digestível, bem como, os teores de proteína bruta, energia digestível, cálcio, fósforo total e fósforo disponível das dietas experimentais foram aqueles que constam em Rostagno et al. (2005) e a relação cálcio:fósforo total foi mantida em 1,35 em todas as dietas experimentais.

As dietas experimentais foram constituídas por milho, farelo de soja, leite desnatado, plasma sanguíneo, lactose, óleo, fosfato bicálcico, calcário, sal, mistura de vitaminas, mistura mineral e aminoácidos (Tabela 1). Lactose foi adicionada às dietas de forma a se garantir um nível mínimo de $11,7 \%$.

As dietas foram umedecidas (50,0\% dieta e $50,0 \%$ água) e fornecidas aos animais de forma controlada em quantidades variáveis em quatro refeições diárias por um período de uma hora por trato, por doze dias. As quantidades de dietas fornecidas foram determinadas em função dos consumos dos animais do tratamento um. As sobras diárias de dietas dos animais do tratamento um foram secas e pesadas e quantidades iguais às consumidas no dia foram fornecidas na refeição seguinte para os leitões de todos os tratamentos, de modo a assegurar consumos iguais por repetição e por tratamento. A cada quatro dias as quantidades de dietas fornecidas foram aumentadas em $20,0 \%$. As diferenças entre os consumos de dietas pelos animais do tratamento um em relação aos consumos dos leitões dos demais tratamentos no primeiro dia do experimento foram adicionadas nos quatro últimos dias do experimento. Aos 28 dias de idade os animais foram desmamados, pesados e transferidos para a creche totalmente fechada, sendo alojados em gaiolas metálicas com 1,6 $\mathrm{m}$ de comprimento $\times 1,0 \mathrm{~m}$ de largura, suspensas à altura de $0,56 \mathrm{~m}$ do chão, com pisos e laterais telados (que permitiram contato visual entre os leitões) e com bebedouros tipo chupeta. Os leitões foram criados em condições de desafio sanitário. O desafio sanitário consistiu no alojamento dos leitões em uma sala de creche que foi também ocupada com animais mais velhos e que não foi limpa e nem desinfetada.

Foi feito aquecimento do ambiente através de lâmpadas incandescentes e a renovação de ar foi realizada pela abertura da porta quatro vezes ao dia durante uma hora no momento de fornecimento de dietas para os leitões.

Os leitões que tiveram diarréias $\mathrm{e}$ temperaturas elevadas foram medicados com uma dose diária injetável no músculo de um mililitro de antibiótico (enrofloxacina). O número de doses foi adotado como critério para avaliação do índice de diarréia sendo que, se um leitão apresentou diarréia por mais de um dia consecutivo, ele recebeu a cada dia dose do antibiótico até a diarréia cessar. Os resultados de diarréia também foram apresentados considerando-se as relações percentuais entre $\mathrm{o}$ tratamento que recebeu maior número de doses $(100,0 \%)$ e os demais tratamentos.

Os leitões foram abatidos após doze dias de experimento de forma humanitária com insensibilização cerebral com choque elétrico e posterior sangramento. Foi coletado o conteúdo intestinal à $30 \mathrm{~cm}$ da alça ileal. $O$ conteúdo intestinal coletado foi acondicionado em potes plásticos esterilizados, identificados que foram imediatamente acomodados em bolsa térmica contendo gelo. Após o abate, no mesmo dia, as amostras devidamente acondicionadas foram encaminhadas para o laboratório. 
Rev. Bras. Saúde Prod. Anim., Salvador, v.14, n.4, p.798-807 out./dez., 2013 http://www.rbspa.ufba.br ISSN 15199940

Tabela 1 Quantidades de ingredientes e composições centesimais das dietas de acordo com o nível de plasma

\begin{tabular}{|c|c|c|c|c|}
\hline \multirow{2}{*}{ Ingredientes } & \multicolumn{4}{|c|}{ Níveis de plasma (\%) } \\
\hline & 0 & 2,5 & 5,0 & 7,5 \\
\hline Milho & 49,94 & 49,51 & 49,65 & 49,30 \\
\hline Farelo de Soja & 25,70 & 25,70 & 25,70 & 25,70 \\
\hline Leite em pó & 16,20 & 11,90 & 5,50 & - \\
\hline Lactose & 2,33 & 4,96 & 8,88 & 12,20 \\
\hline Plasma SP & - & 2,50 & 5,00 & 7,50 \\
\hline Óleo de Soja & 2,42 & 1,82 & 1,46 & 1,18 \\
\hline Fosfato Bicálcico & 1,60 & 1,75 & 1,92 & 2,07 \\
\hline Calcário & 0,70 & 0,70 & 0,71 & 0,85 \\
\hline Sal & 0,35 & 0,35 & 0,35 & 0,35 \\
\hline Mistura de Vitamínas ${ }^{1}$ & 0,15 & 0,15 & 0,15 & 0,15 \\
\hline Mistura Mineral $^{2}$ & 0,10 & 0,10 & 0,10 & 0,10 \\
\hline L-Lisina HCL (98\%) & 0,231 & 0,256 & 0,285 & 0,293 \\
\hline DL-Metionina (98\%) & 0,152 & 0,168 & 0,176 & 0,182 \\
\hline L-Treonina $(98 \%)$ & 0,128 & 0,131 & 0,123 & 0,125 \\
\hline \multicolumn{5}{|l|}{ Composição calculada $^{3}$} \\
\hline $\mathrm{ED}(\mathrm{kcal} / \mathrm{kg})$ & 3500 & 3500 & 3500 & 3500 \\
\hline Proteína bruta (\%) & 21,20 & 21,53 & 21,20 & 21,13 \\
\hline $\mathrm{Ca}(\%)$ & 0,886 & 0,892 & 0,882 & 0,891 \\
\hline Ptotal $(\%)$ & 0,652 & 0,661 & 0,658 & 0,660 \\
\hline Pdig (\%) & 0,482 & 0,491 & 0,488 & 0,490 \\
\hline $\mathrm{Na}(\%)$ & 0,270 & 0,274 & 0,280 & 0,280 \\
\hline Lisina dig. (\%) & 1,450 & 1,470 & 1,476 & 1,511 \\
\hline Treonina dig. (\%) & 0,913 & 0,926 & 0,930 & 0,952 \\
\hline Triptofano dig. (\%) & 0,247 & 0,250 & 0,251 & 0,257 \\
\hline Met+Cis dig. (\%) & 0,812 & 0,823 & 0,826 & 0,846 \\
\hline Arginina dig. (\%) & 1,055 & 1,134 & 1,206 & 1,280 \\
\hline Valina dig. $(\%)$ & 0,762 & 0,850 & 0,929 & 1,011 \\
\hline Isoleucina (\%) & 0,708 & 0,732 & 0,745 & 0,762 \\
\hline
\end{tabular}

${ }^{I}$ Contendo por kg: 12000 UI de Vitamina A; 2250 UI de Vitamina D3; $27 \mathrm{mg}$ de Vitamina E; 3mg de Vitamina K; 2,25mg de Tiamina; 6mg de Riboflavina; 2,25mg de Piridoxina; 27 mcg de vitamina B12; $400 \mathrm{mcg}$ de Ácido fólico; $150 \mathrm{mcg}$ de Biotina; $22,5 \mathrm{mg}$ de Ácido pantotênico e $45 \mathrm{mg}$ de Niacina.

${ }^{2}$ Contendo por kg: $88 \mathrm{mg}$ de Fe; $15 \mathrm{mg}$ de $\mathrm{Cu} ; 80 \mathrm{mg}$ de $\mathrm{Zn} ; 45 \mathrm{mg}$ de $\mathrm{Mn} ; 1 \mathrm{mg}$ de I e $300 \mathrm{mcg}$ de Se.

${ }^{3}$ Segundo Rostagno et al. (2005).

A amostra do conteúdo intestinal, depois de seca, foi pesada. A contagem de unidades formadora de colônias de bactérias (ufc) por grama de amostra seca foi realizada da seguinte forma: as amostras foram homogeneizadas por inversão de pontas e o conteúdo foi drenado para um becker após a lavagem das mucosas com cinco $\mathrm{ml}$ de água destilada; o conteúdo coletado foi pesado e após pesagem foi retirada uma alíquota de um mililitro que foi diluído em dez mililitro de água destilada e a partir desta diluição foram realizadas outras diluições até atingir a diluição de 1:10.000.000; deste conteúdo foi retirado um mililitro que foi inoculado em placas de meio de cultura específico contendo alfa ou beta amilase e, as placas foram incubadas a $35^{\circ} \mathrm{C}$ por 24 horas e após este período foram realizadas as contagens de E. coli. Os 
resultados foram expressos na base dez de ufc E. coli por grama (g) de matéria seca da amostra.

$\mathrm{O}$ intestino delgado foi dissecado em sessões transversais de dois centímetros no duodeno, no jejuno e no íleo. As amostras, imediatamente após coletadas, foram imersas em solução fixadora (solução de Bouin) onde permaneceram por 24 horas. Em seguida elas foram lavadas e transferidas para a solução de álcool etílico a 70,0\%. Após isto, os segmentos intestinais foram recortados em fragmentos de aproximadamente um centímetro, diafanizados em benzol e incluídos em parafina. Utilizando-se um micrótomo, foram produzidas seções com sete micrometros de espessura sendo que entre uma seção e a subseqüente foram eliminadas 30 . As seções foram coloridas com hematoxilina e eosina e depois preparadas na forma de cortes histológicos em lâminas no Laboratório de Histologia do Departamento de Veterinária da Universidade Federal de Viçosa.

As medidas de altura de vilosidade foram realizadas através de analisador de imagem acoplado a um microscópio óptico com ampliação de 125 vezes o tamanho da imagem e para cada lâmina foram feitas 30 medidas no Laboratório de Nutrição Animal do Departamento de Zootecnia da Universidade Federal de Viçosa.

Os resultados de ganho de peso (GP) e conversão alimentar (CA), altura de vilosidades (AV), profundidade de criptas (PC) e ufc de E. coli por grama de amostra foram submetidos à análise de variância, utilizando-se o Sistema de Análise Estatística e Genética, desenvolvido na Universidade Federal de Viçosa - MG (UFV, 2005).

As medias de GP e CA foram comparadas entre tratamentos pelo teste de Dunnet com $\alpha<0,05$, enquanto que, as médias de ufc/g, alturas de vilosidades e profundidades de cripta foram comparadas entre tratamentos pelo teste de Dunnet com $\alpha<0,05$. A ANOVA dos dados referentes à ufc/g foi viabilizada transformando-se os resultados pela função $\mathrm{y}=\log \mathrm{x}$, em que $\mathrm{x}$ foi ufc/g. Foram realizadas análises descritivas relacionando-se a ocorrência de diarréias com o número de ufc de $E$. coli/g de amostra.

\section{RESULTADOS E DISCUSSÃO}

Foram constatadas diferenças significativas entre os tratamentos com relação aos ganhos de peso, às conversões alimentares e às quantidades de colônias de E. coli (Tabela 2). Foi observado que o ganho de peso aumentou $(\mathrm{P} \leq 0,05)$ e a conversão alimentar melhorou $(\mathrm{P} \leq 0,05)$ com a adição de 2,$5 ; 5,0$ e 7,5\% de plasma sangüíneo nas rações em relação aos animais submetidos ao tratamento controle. Barbosa et al. (2007), Assis Junior et al. (2009) e Formigoni (2012) também não observaram efeito significativo nos níveis de inclusão de plasma na dieta sobre o consumo de ração e relacionaram esse resultado ao estresse decorrente de adaptações fisiológicas e digestivas do desmame. Provavelmente, a melhora observada sobre o ganho de peso e conversão alimentar dos animais esteja relacionada à diminuição dos efeitos negativos as vilosidades do intestino delgado e conseqüentemente sobre a ocorrência de diarréias causadas pelo estresse pósdesmame, fatores críticos ao bom desempenho dos leitões.

Os animais submetidos às dietas contendo plasma sangǘneo apresentaram menores $(\mathrm{P}<0,10)$ quantidades de $E$. coli no intestino delgado que os animais que receberam 
dietas sem plasma. Embora não analisado estatisticamente, constatou-se que a aplicação de dosagens de antibióticos nos animais submetidos a dietas sem plasma foi bem maior do que as dosagens aplicadas nos animais que receberam dietas contendo plasma.

Tabela 2 Peso inicial (PI), desempenho, índice de diarréia (ID) e unidades formadoras de colônias de E. coli (UFC) em leitões desmamados aos 28 dias de idade consumindo dietas com diferentes níveis de plasma

\begin{tabular}{|c|c|c|c|c|c|c|}
\hline \multirow{2}{*}{ Parâmetros } & \multicolumn{4}{|c|}{ Níveis de plasma (\%) } & \multirow{2}{*}{$\mathrm{CV}(\%)$} & \multirow{2}{*}{$\mathrm{P}$} \\
\hline & 0,0 & 2,5 & 5,0 & 7,5 & & \\
\hline Peso inicial (kg) & 8,65 & 8,62 & 8,82 & 8,82 & - & - \\
\hline Consumo de ração (g/dia) & 542 & 542 & 542 & 542 & - & - \\
\hline Ganho de peso $^{1}$ (g/dia) & $408^{\mathrm{b}}$ & $451^{\mathrm{a}}$ & $448^{\mathrm{a}}$ & $449^{\mathrm{a}}$ & 7,3 & 0,037 \\
\hline Conversão alimentar $^{1}(\mathrm{~g} / \mathrm{g})$ & $1,33^{\mathrm{b}}$ & $1,20^{\mathrm{a}}$ & $1,21^{\mathrm{a}}$ & $1,21^{\mathrm{a}}$ & 9,7 & 0,049 \\
\hline Índice de diarréia (un.) & 15 & 4 & 1 & 1 & - & - \\
\hline Índice de diarreia $(\%)$ & 100,0 & 27,0 & 6,6 & 6,6 & - & - \\
\hline $\mathrm{UFC}^{2}(\mathrm{~g} / \mathrm{ml})$ & $8,9 \times 10^{9 \mathrm{~b}}$ & $1,3 \times 10^{8 \mathrm{a}}$ & $7,9 \times 10^{7 a}$ & $2,0 \times 10^{7 \mathrm{a}}$ & 34,6 & 0,018 \\
\hline
\end{tabular}

${ }^{\mathrm{T}}$ Médias seguidas de letras diferentes na linha diferem entre si pelo teste de Dunnet $(\mathrm{P}<0,05)$.

${ }^{2}$ Médias seguidas de letras diferentes na linha diferem entre si pelo teste de Dunnet $(\mathrm{P}<0,10)$.

Alguns autores têm sugerido que a melhora no desempenho de leitões alimentados com plasma pode ocorrer em razão direta do aumento do consumo de ração (GATTÁS et al., 2008; BARBOSA et al., 2012), enquanto que outros têm sugerido que os benefícios do plasma podem ir além do simples estímulo ao consumo voluntário, como, por exemplo, devido à presença de imunoglobulinas específicas (BARBOSA et al., 2007; GATTÁS et al., 2008). Estas premissas têm sido baseadas em resultados de pesquisas em que os ganhos de peso e os consumos de ração dos leitões recebendo plasma sangüíneo têm sido mais evidentes em ambientes desafiados do que em ambientes considerados limpos (CAMPBELL et al., 2010). Observa-se ainda que quanto maior o desafio ambiental, mais consistente parece ser a resposta positiva da inclusão do plasma. Van der Peet-Schwering \& Binnendijk (1995) observaram redução de patologias intestinais quando os animais receberam dietas com suplementação de plasma sangüíneo. Por outro lado, Van Dijk et al. (2002) não observaram efeitos do plasma sanguíneo sobre a morfologia intestinal de suínos nem sobre o número de colônias bacterianas nas fezes.

Bosi et al. (2004) sugeriram que o plasma sangüíneo atua sobre as infecções patogênicas devido ao aumento da imunidade local e/ou a redução da adesão de patógenos à mucosa causada pelas imunoglobulinas e glicoproteínas presentes nele (atuando como núcleos de enlace nas fimbrias da E. coli). Estes efeitos podem estar associados de forma direta com a melhora do desempenho dos leitões, pois uma maior proliferação de microrganismos patogênicos, como a Escherichia coli, pode ter como conseqüência às diarréias (YI et al., 2005). Além disso, o animal debilitado por diarréias ainda pode ter a 
necessidade de desviar nutrientes para manutenção do sistema imune ativado. Provavelmente, em função disto, os animais do tratamento sem plasma sangüíneo no presente estudo tenham tido menores ganhos de peso que os animais que se alimentaram de dietas contendo plasma sangüíneo. Como, os consumos de ração foram os mesmos, isto reverberou em melhores conversões alimentares. Bosi et al. (2004) associaram a diminuição no desempenho dos animais ao aumento de citocinas circulantes, indicando ativação do sistema imune.

No presente experimento houve uma relação direta entre a quantidade de colônias de $E$. coli com a ocorrência de diarréias e com o desempenho dos animais. Esses resultados foram similares aos observados por Coffey \& Cromwell (2001), Van Dijk et al. (2001) e Lora et al. (2010). Estes pesquisadores, também, associaram a redução das quantidades de unidades formadoras de colônias de $E$. coli à melhora no desempenho dos animais. De maneira semelhante Barbosa et al. (2012) concluíram que a inclusão de plasma sanguíneo em dietas para leitões desmamados aos 35 dias de idade tem efeito direto sobre as ufc de E. coli por grama de amostra no intestino delgado e resulta em diminuição do índice de diarréias, enquanto os níveis de 5,0 e $7,5 \%$ de plasma também melhoram o desempenho de leitões desmamados aos 35 dias de idade e criados em condições de desafio sanitário.

Não foram observadas efeitos do plasma sangüíneo sobre a altura de vilosidades no duodeno, jejuno e íleo de leitões desmamados aos 28 dias de idade (Tabela 3). Do mesmo modo, Nofrarías et al. (2006) também não observaram efeitos do plasma sobre a altura de vilosidade e profundidade de cripta no intestino delgado de leitões desmamados aos 20 dias e eles sugeriram que o plasma não teria efeitos tróficos específicos tanto no intestino delgado quanto no intestino grosso, não evitando, portanto, danos causados à parede intestinal associado com o desmame.

Tabela 3 Altura de vilosidades e profundidade de criptas dos diferentes segmentos do ID de leitões desmamados aos 28 dias de idade consumindo diferentes níveis de plasma

\begin{tabular}{lcccccc}
\hline \multirow{2}{*}{ Variáveis } & \multicolumn{3}{c}{ Nível de plasma sanguíneo na ração $(\%)$} & CV & \multirow{2}{*}{ P } \\
\cline { 2 - 5 } & 0,0 & 2,5 & 5,0 & 7,5 & & \\
\hline Altura de vilosidades $(\mu \mathrm{m})$ no Duodeno & 370 & 333 & 315 & 359 & 15,5 & 0,121 \\
Jejuno & 343 & 286 & 338 & 308 & 17,9 & 0,184 \\
Íleo & 282 & 244 & 339 & 296 & 14,2 & 0,084 \\
Profundidade de cripta $(\mu \mathrm{m})$ no Duodeno & 301 & 308 & 275 & 345 & 8,0 & 0,071 \\
Jejuno & 282 & 295 & 298 & 321 & 10,0 & 0,107 \\
Íleo & 254 & 244 & 239 & 273 & 11,4 & 0,113 \\
\hline
\end{tabular}

Torrallardona et al. (2003), trabalhando com animais desmamados aos 24 dias de idade e desafiados com Escherichia coli K99 também não observaram melhora sobre os parâmetros avaliados (altura de vilosidade e profundidade de cripta no intestino delgado) diante da inclusão de $7,0 \%$ de plasma sangüíneo nas dietas. 
Por outro lado, Yi et al. (2005) verificaram maiores alturas de vilosidades nas porções proximal e média do jejuno e também no íleo dos leitões que receberam dieta com plasma. Neste trabalho, no entanto, os animais foram desmamados mais precocemente, aos 17 dias. Essa disparidade de resultados pode ser indicativo de que os efeitos benéficos da inclusão do plasma nas dietas podem estar relacionados com a idade do animal ao desmame e, conseqüentemente, com o desenvolvimento de suas defesas e de seu sistema enzimático, pois animais mais velhos podem estar mais adaptados a digerir alimentos de origem vegetal e portanto menos susceptíveis a injúrias na parede intestinal.

Portanto, como base nos resultados de desempenho, quantidade de colônias de E. coli e de estrutura intestinal, pode-se inferir que há efeitos do plasma sangüíneo após o desmame aos 28 dias de idade, não só o de aumentar $o$ consumo de ração e que, nesses estudo, não foi a estrutura intestinal que melhorou o desempenho e sim o controle de colônias de bactérias. Assim, conclui-se que a inclusão de plasma sangüíneo na proporção mínima de 2,5\% aumenta ganho de peso, melhora conversão alimentar e reduz a incidência de colônias de $E$. coli no intestino de leitões desmamados aos 28 dias de idade criados em condições de desafio, mas não afeta a estrutura intestinal.

\section{AGRADECIMENTOS}

À Fundação de Amparo à Pesquisa de Minas Gerais FAPEMIG pelo apoio financeiro para realização dessa pesquisa.

\section{REFERÊNCIAS}

ASSIS JÚNIOR, F.I; FERREIRA, A.S.; DONZELE, J.L. DETMANN, E.; BARBOSA, F.F.; SOUZA JUNIOR, A.H. Níveis de plasma sanguíneo em dietas pós-desmame para leitões desmamados aos 28 dias de idade.

Revista Brasileira de Zootecnia, v.38, n.5, p.843-849, 2009.

BARBOSA, F.F.; FERREIRA, A.S.; GATTÁS, G.; SILVA. F.C.O.; DONZELE, J.L.; BRUSTOLINI, P.C.; LOPES, D.C. Níveis de plasma sanguíneo em pó em dietas para leitões desmamados aos 21 dias de idade.

Revista Brasileira de Zootecnia, V.36, n.4, p.1052-1060.2007. (Supl).

BARBOSA, F.F.; SILVA, F.C.O.; FERREIRA, A.S.; PUPA, J.M.R.; BRUSTOLINI, P.C.; CAMPOS, P.F. Efeitos de plasma sangüíneo sobre vilosidades, desenvolvimento bacteriano e desempenho de leitões criados em condições de desafio pós-desmame aos 35 dias. Revista Brasileira da Saúde e Produção Animal [online], v.13, n.2, p.469-479, 2012.

BOSI, P.; CASINI, L.; FINAMORE, A. CREMOKOLINI, C.; MERIALDI, G.; TREVISI, P.; NOBILI, F. AND MENGHERI, E. Spray-dried plasma improves growth performance and reduces inflammatory status of weaned pigs challenged with enterotoxigenic Escherichia coli K88. Journal of Animal Science, v.82, p.1764-1772, 2004.

CAMPBELL, J.M.; POLO, J.; RUSSEL, L.; CRENSHAW J. D. Review of spraydried plasma's impact on intestinal barrier function. Livestock Production Science, v.133, n.1, p.239-241, 2010. 
CERA, K.R.; MAHAN, D.C.; CROSS, R.F. Effect of age, weaning and postweaning diet on small intestinal growth and jejunal morphology in young swine. Journal of Animal Science, v. 66, n.2, p.574-584, 2010.

COFFEY, R.D.; CROMWELL, G.L. Use of spray-dried animal plasma in diets for weanling pigs. Pig News and

Information, v.22, p.39-48, 2001.

FORMIGONI, A.S. Seqüências de níveis de plasma sangüíneo em pó para leitões desmamados aos 21 dias de idade. 2012. 29p. Tese (Doutorado em Zootecnia) - Universidade Federal de Viçosa, Viçosa.

GATTÁS, G.; FERREIRA, A.S.; BARBOSA, F.F.; SILVA, F.C.O.; DONZELE, J.L.; LOPES, D.C.Níveis de plasma sanguíneo em pó em dietas para leitões desmamados aos 14 dias de idade. Revista Brasileira de Zootecnia, v.37, n.2, p.278-285, 2008.

KLASING, K.C.; JOHNSTONE, B.J.; BENSON, B.N. Implications on and immune response on growth and nutrient requirements of chicken. In: HARESING, W.; COLE, D.J.A (Eds). Recent

Advances in Animal Nutrition. Lodon, 1991. p.135-146.

LORA, G.G.; FERREIRA, A.S.; SILVA, F.C.O.; GRANA, A.L.; ARAUJO, W.A.G.; PEREIRA, C.M.C. Plasma sangüíneo em dietas sem antibiótico para leitões desmamados aos 21 dias de idade. Revista Brasileira de Saúde e Produção Animal [online], v.11, p.815-826, 2010.

NOFRARÍAS, M.; MANZANILLA, E.G.; PUJOLS, J.; GIBERT, X.;. MAJO, N. ; SEGALES, J. ; GASA, J. Effects of spray-dried porcine plasma and plant extracts on intestinal morphology and on leukocyte cell subsets of weaned pigs. Journal of

Animal Science, v.84, p.2735-2742, 2006.

ROPPA, L. Uso de produtos lácteos nas rações pré-iniciais dos suínos.

Suinocultura Industrial, v.7, n.74, p.16-19, 1998.

ROSTAGNO, H.S.; ALBINO, L.F.T.; DONZELE, J.L. GOMES, P.C.; OLIVEIRA, R.F.; LOPES, D.C; FERREIRA, A.S.; BARRETO, L.S.T.

Tabelas brasileiras para aves $\mathrm{e}$ suínos: composição de alimentos e exigências nutricionais. Viçosa, MG: Universidade Federal de Viçosa, 2005. $186 \mathrm{p}$.

TORRALLARDONA, D.; CONDE, M.R.; BADIOLA, I.; POLO, J.; BRUFAU, J. Effect of fishmeal replacement with spray-dried animal plasma and colistin on intestinal structure, intestinal microbiology, and performance of weanling pigs challenged with Escherichia coli K99. Journal of Animal Science, v.81, p.1220-1226, 2003.

VAN DIJK, A.J.; EVERTS, H.; NABUURS, M.J.A.; MARGRY, R.J.C.F.; BEYNEN, A.C. Growth performance of weanling pigs fed spray-dried animal plasma: A review. Livestock Production Science, v.68, p.263-274, 2001.

VAN DIJK, A.J.; NIEWOLD, T.A.; NABUURS, M.J.; VAN HEES, J.; DE BOT, P. STOCKHOFE-ZURWIEDEN, N.; UBBINK-BLANKSMA, M.; BEYNEN, A.C. Small intestinal morphology and disaccharidase activities in early-weaned piglets fed a diet containing spraydried porcine plasma. Journal Veterinary Medicine A, v.49, p.81-86, 2002. 
UNIVERSIDADE FEDERAL DE VIÇOSA - UFV. SAEG - Sistemas de Análises Estatísticas e Genéticas. Versão 8.0. Viçosa, MG, 2005.

VAN DER PEET-SCHWERING, C.M.C.; BINNENDIJK, G. P. The effect of spray-dried porcine plasma in diets with differrent protein sources on the performance of weanling piglets. Report Rosmalen: Praktijkonderzoek Varkenshouderij; 1995. p.1-137.
YI, G.F.; CARROLL, J.A.; ALLEE, G.L.; GAINES, A.M.; KENDALL, D.C.; USRY, J.L.; TORIDE, Y.; IZURU, S. Effect of glutamine and spray-dried plasma on growth performance, small intestinal morphology, and immune responses of Escherichia coli K88+-challenged weaned pigs. Journal of Animal Science, v.83, p. 634-643, 2005.

Data de recebimento: $24 / 05 / 2013$ Data de aprovação: 05/12/2013 